\title{
ЛЕКСИЧЕСКИЕ ОСОБЕННОСТИ ГАЗЕТНЫХ ЗАГОЛОВКОВ (НА МАТЕРИАЛЕ НЕМЕЦКОГО ЯЗЫКА)
}

\section{LEXICAL FEATURES OF NEWSPAPER HEADLINES (ON THE EXAMPLE OF THE GERMAN LANGUAGE)}

\section{E. Lavrichshevo}

Summary: The article deals with the features of newspaper headlines. The analysis of the linguistic material is carried out, the nominative field of newspaper and publicistic texts is described. Particular attention is paid to the lexical features of the headlines: the use of emotionally colored vocabulary, phraseological units, borrowings, abbreviations and acronyms. The author draws a conclusion about the role of lexical features in the headline.

Keywords: publicistic style, nominative field, phraseological unit, evaluativity, functions of headlines.

\author{
Лаврищева Екатерина Владимировна \\ к.филол.н., ФГБОУВО «Елецкий государственный \\ университет им. И.А. Бунина» \\ eklav@mail.ru
}

Аннотация: В статье рассматриваются особенности газетных заголовков. Проводится анализ языкового материала, описывается номинативное поле газетно-публицистических текстов. Особое внимание уделяется лексическим особенностям заголовков: использование эмоционально-окрашенной лексики, фразеологизмов, заимствований, аббревиатур и сокращений. Делается вывод о роли лексических особенностей в заголовке.

Ключевые слова: публицистический стиль, номинативное поле, фразеологизм, оценочность, функции заголовков.

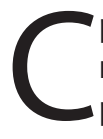

редства массовой информации всегда играли важную роль в жизни общества, способствуя формированию общественного мнения. Открывая газету или журнал, первое, что видит читатель - это заголовок.

Яркий, броский, интригующий заголовок расценивается в качестве кульминации высокого журналистского мастерства. Для достижения такого эффекта журналисты тщательно отбирают формы выражения на всех языковых уровнях: лексическом, синтаксическом и морфологическом. Однако в современном языкознании изучение лексико-стилистических особенностей немецких газетно-журнальных статей носит фрагментарный характер и нуждается в систематизации.

В данной работе нами были проанализированы около 300 заголовков статей из немецкого журнала «Der Spiegel».

И.В. Арнольд отмечает, что стилеобразующими факторами для газетных заголовков являются те же факторы, что и для газетного стиля вообще, но при этом ученый подчеркивает, что в заголовке все эти факторы действуют особенно сильно. Кроме того требования компрессии информации и привлечения внимания и интереса читателя оказываются особенно важными [1:183].

В качестве главных стилеобразующих особенностей газетно-публицистического текста можно выделить стандарт и экспрессия. С целью реализации информативной функции журналисты используют нейтральную лекси- ку, которая служит для более точного и безоценочного описания предметов и явлений. Однако для реализации одной из основных целей газетно-публицистического текста, а именно привлечения внимания читателей, воздействия на них достаточно часто используется эмоционально-оценочная лексика.

Номинативное ядро лексического фонда газетно-публицистического текста образует терминологическая лексика, которая включает в себя названия явлений и понятий из различных сфер общественно-политической жизни:

- экономическая сфера: die Marktwirtschaft, die Wirtschaftswoche, der Arbeitgeberpräsident, die Weltbank, der Geschäftsklimabericht, der Währungsfond, der Shopmanager, Grenzkontrollen für Waren, Probleme bei Importen und Exporten;

- политическаясфера:diepolitische Verantwortung;die Schmutzkampagne; neue Formen der Stimmabgabe; das Linksbündnis; die Außenpolitik; kompromissfähig; Bundestagsabgeordnete;

- социальная сфера: das Coronavirus, die die Impfbereitschaft, die Pandemie, ungeimpft, die Kindeswohlgefährdung, die Klimakrise, die Gleichberechtigung, die Feministin.

Журналист стремится к тому, чтобы сделать читателя своим сторонником, что приводит к употреблению в газетно-публицистическом тексте большого количества эмоционально-оценочных лексических средств, которые включают в себя качественно-оценочные существи- 
тельные и прилагательные, фразеологические единицы, разнообразные тропы. Оценочность при этом выступает В качестве основного принципа, который объединяет различные разряды лексики газетно-публицистического стиля.

Для экспрессии и выразительности, а также для привлечения внимания читателей в заголовках могут быть использованы модальные частицы doch, sicher и др.: Schießen ja, aber bitte klimaneutral; Hungrig? Aber sicher!; Wechsel ja, aber wohin?; So nah und doch so fern.

В публицистических текстах также используется разговорная лексика в качестве стилистического приема интимизации, снижения официального тона. Разговорно-окрашенная лексика придает заголовку эмоциональную окраску, делает его более экспрессивным, образным, привлекает внимание читателей к той или иной статье: Fakt you; Narziss und Schoßhund; Wilders trumt auf; Schwaches drittes Quartal: Chinas Wachstum kühlt auf Einjahrestief ab; Neue Erkenntnisse zum Aufstieg der Hanse: Die Mafia des Mittelalters; Katastrophenschutz in Deutschland: «Da lacht die ganze Welt drüber!»

Основная цель журналистов - быть как можно ближе к читателю, именно поэтому в газетно-журнальных заголовках часто встречается эмоционально окрашенная лексика с экспрессивной семантикой. Наиболее ярким примером служат фразеологические единицы и устойчивые словосочетания, лежащие в основе газетно-журнальных заголовков: Die Welt startet verhalten ins neue Jahr; Was die neuen Corona-Beschlüsse bringen: Bremsen um jeden Preis; «Kameltreiber»-Skandal bei Olympia: «Mein Bruder hat sein wahres Gesicht gezeigt»; Steigende Coronainfektionen in Spanien: Plötzlich steht der Sommer wieder auf dem Spiel; Teresa Enke kritisiert Depressions-Aussage: «Lieber Boris Becker, Dein Ernst?»; Union: Erste CDU-Abgeordnete bringen Brinkhaus als Kanzlerkandidat ins Spiel.

Анализ языкового материала показывает, что для заголовков типичным является также употребление большого количества сокращений и аббревиатур, которые выступают средством языковой экономии. Новые или не очень часто употребляемые сложносокращенные слова и аббревиатуры также способны вызвать интерес читателей. При этом следует отметить, что если не знать смысла того или иного сокращенного слова, то почти невозможно понять смысл заголовка, для расшифровки сокращений и аббревиатур иногда необходимо использовать справочную литературу.

В проанализированных нами заголовках чаще всего встречаются аббревиатуры названий стран, партий, организаций: Impfstoffstreit in der EU: Kurz scheitert mit Blockadeversuch; USA: Vier Tote nach Schießerei - Täter kannte seine Opfer; Union: Erste CDU-Abgeordnete bringen Brinkhaus als
Kanzlerkandidat ins Spiel; Programmreform vorgestellt: $A R D$ will mehr junges Publikum ansprechen; Affäre um DFB und Vermarkter Infront: "Geil auf das Rad»; LOL: Last One Laughing" bei Amazon Prime: Wer lacht, verliert.

Так как люди предпочитают читать актуальные новости о событиях в жизни знаменитых людей, в газетно-журнальных заголовках можно встретить большое количество имен собственных, например: Helene Fischer, ganz privat (Helene Fischer - немецкая певица); Endlich keinen Sex mehr und keinen Justin Biber! (Justin Biber - канадский поп-R\&В-певец); Der Fall Kramer (Christoph Kramer - немецкий футболист); Schäuble will Länder früh einbilden (Wolfgang Schäuble - немецкий политик из партии ХДС); P.D. James (P.D. James - британская писательница, автор популярных детективов); Wer ist Kim Kardashian? (Kim Kardashian - американская звезда реалити-шоу, актриса, фотомодель); Tarantino für Arme (Tarantino - американский кинорежиссер, сценарист, актер, кинопродюсер и кинооператор); Tebarzt begnügt sich jetzt mit 180 Quadratmetern (Franz-Peter Tebarzt-van Elst - католический прелат, епископ Лимбурга с 28 ноября 2007 года по 26 марта 2014 года).

Однако чаще всего в связи с обостренной политической ситуацией в мире в газетно-журнальных заголовках часто всплывают имена президента России, президента США, а также канцлера Германии, известных политиков: Die Lage am Morgen: Macht Kurz den Putin?; Drohung statt Gratulation: Putin warnt russischen Friedensnobelpreisträger; G20-Gipfel zu Afghanistan: Merkel besteht trotz Taliban auf Hilfsgelder; Inhaftierter Kremlkritiker: Nawalny nach eigenen Angaben als Terrorist eingestuft; US-Kongress untersucht Kapitol-Sturm: Wie Trump seine Gegner ausspielen will; Widerstand von Senator Joe Manchin: Weißes Haus schwächt offenbar seine Klimaschutzpläne ab; Bill Clinton erholt sich auf Intensivstation: "Zustand war nie lebensbedrohlich»; Kongressausschuss zur Kapitol-Erstürmung: Biden blockiert Trumps Geheimhaltungsversuch.

В связи с постоянным усилением влияния английского языка на другие языки, в том числе и на немецкий, в 20 заголовках из 300 проанализированных содержатся англицизмы и американизмы: Fakt you; Wilders trumt auf; Britisches Königshaus: Royals unterstützen laut Vertreter die Black-Lives-Matter-Bewegung; Schläger und Gentleman; Glamour von der Farm; Hürden für die Hipster; Die Youtube-Schule; Last Christmas.

Заимствованная лексика в приведенных выше заголовках отражает социальную жизнь современного общества: Glamour, Black Lives Matter, Youtube, Hipster. Иcпользуя в заголовках такие лексические единицы, автор старается привлечь внимание молодежи и тех людей, которые хотят идти в ногу со временем и знать все о современном мире. 
Заимствования выполняют не только прямую, номинативную функцию, для обозначения новых реалий, но и стилистическую. Заимствования придают газетно-журнальному заголовку образность, выполняя при этом не только номинативную, но и экспрессивную функцию. Употребление заимствованной лексики в заголовках способствует привнесению «иллюзии уникальности», усилению впечатления оригинальности и новизны, неповторимости и значимости той или иной газетно-журнальной статьи, а также придает аттрактивность немецким газетно-журнальным заголовкам.

Проанализированный материал показывает, что языковые средства оживляют, актуализируют газетно-жур- нальный заголовок, а вместе с ним и ниже напечатанный публицистический текст. Разнообразие приемов словесного выражения, усиление экспрессивности, сопровождающей даже простейшую тему, при одновременной общепонятности должны служить одним из принципов создания газетно-журнального заголовка.

Основная цель газетно-журнального заголовка не столько проинформировать, сколько сформировать у читателя яркий, четкий образ, что достигается с помощью использования системы изобразительно-выразительных средств языка, которые привносят в объективную информацию дополнительную, субъективную направленность.

\section{ЛИТЕРАТУРА}

1. Арнольд И.В. Семантика. Стилистика. Интертекстуальность: Сб. ст. / Науч. ред. Бухаркин П.Е. — СПб.: Изд-во С.Петерб. ун-та, 1999. - 444 с.

2. Милостивая А.И. Социопрагматические типы текста немецкой газеты: Автореф. дис.. канд. филол. наук / А.И. Милостивая. - Пятигорск, 2001. - 20 с.

3. Покровская Е.В. Газета в современной культурно-речевой ситуации // Русская речь. 2005. - № 5. - С. 69-77.

(с) Лаврищева Екатерина Владимировна (eklav@mail.ru).

Журнал «Современная наука: актуальные проблемы теории и практики»

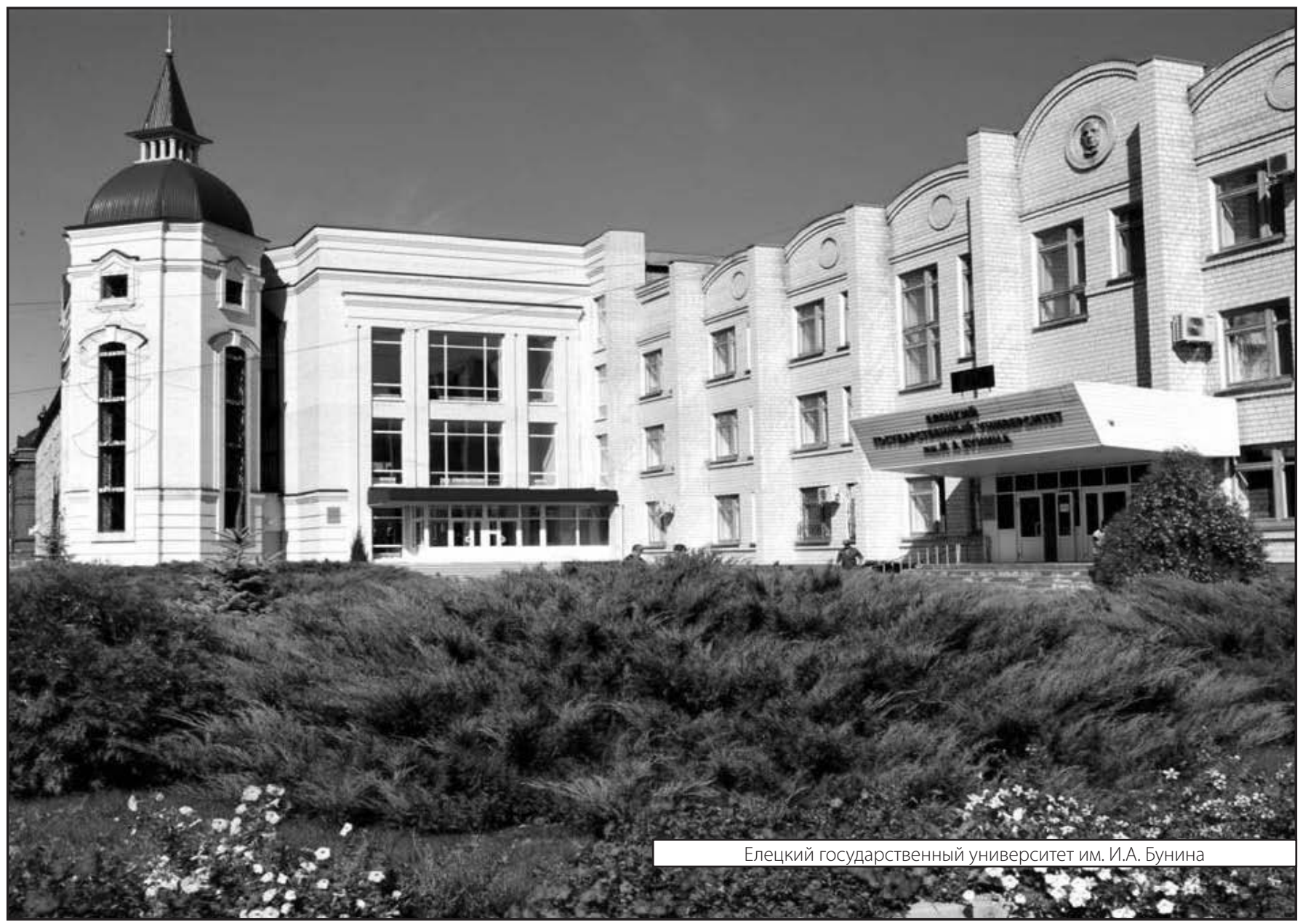

